\title{
BARTONELOSIS (FIEBRE DE LA OROYA O VERRUGA PERUANA) ¿ENFERMEDAD OCUPACIONAL?
}

\author{
CÉSAR GONZÁLES R. (1), CIRO MAGUIÑA V. (2), FELIPE HERAS M. (3), \\ LUIS CONDE-SALAZAR G (4)
}

\author{
(1) Dermatólogo Adjunto - Internista \\ Hospital Nacional Alberto Sabogal Sologuren Callao - Perú. \\ (2) Dermatólogo Adjunto especialista en Enfermedades Tropicales. \\ Instituto de Medicina Tropical Alexander Von Humboldt \\ Universidad Peruana Cayetano Heredia Lima - Perú. \\ (3) Dermatólogo Adjunto - Servicio de Dermatología Laboral \\ Escuela Nacional de Medicina del Trabajo - Instituto de Salud Carlos III - Madrid. \\ (4) Dermatólogo Jefe - Servicio de Dermatología Laboral \\ Escuela Nacional de Medicina del Trabajo- Instituto de Salud Carlos III - Madrid.
}

\section{RESUMEN}

La Bartonella bacilliformis es un parásito bacteriano intracelular facultativo de los eritrocitos humanos y de las células endoteliales. La enfermedad de Carrión, fiebre de La Oroya y Verruga Peruana son todos términos que describen las consecuencias patológicas de la infección humana por Bartonella bacilliformis. (1)

Aunque las infecciones que involucran especies de Bartonella, tales como Bartonella henselae y Bartonella quintana, ocurren en todo el mundo, la enfermedad de Carrión es endémica únicamente en Sudamérica. (14)

Las infecciones por B. bacilliformis son un problema de salud en numerosas áreas rurales de Sudamérica y para los viajeros que visitan esas regiones. Se han reportado brotes de bartonelosis en las regiones montañosas de Perú, Ecuador y Colombia. (1)

La Lutzomyia verrucarum es el principal vector para la transmisión de la bacteria al ser humano; la hembra del mosquito transmite el patógeno durante su alimentación nocturna de sangre humana. Presumiblemente el insecto se alimenta de sangre de un individuo infectado y disemina el patógeno por medio de su saliva durante la siguiente ingesta de sangre. La bacteria no es contagiosa entre humanos. (1)

Presentamos un enfoque laboral de la enfermedad en trabajadores que realizan desplazamientos continuos a zonas endémicas y analizamos sus posibles consecuencias.

\section{PALABRAS CLAVES}

Bartonelosis, enfermedad de Carrión, verruga peruana, lutzomyia, bartonella, laboral, zonas endémicas.

\section{ABSTRACT}

Bartonella bacilliformis is a facultative intracellular bacterial parasite of human erythrocytes and endotelial cells. Carrion's disease, Oroya fever and Peruvian wart are all terms describing the pathological consequences of human infection with Bartonella bacilliformis. (1) Although infections involving the Bartonella species, such as Bartonella henselae and Bartonella Quintana occur worldwide, Carrion's disease is uniquely endemic to South America. (14)

Bartonella baciliformis infections are a health problem in many rural areas of South America and to travellers who visit these regions.

Outbreaks of Bartonellosis have been reported in the mountainous regions of Peru, Ecuador and Colombia.(1)

The Lutzomyia verrucarum is the main vector for transmission of the bacteria to humans. The female sandfly transmits the pathogen during nocturnal blood feeding on humans. Presumably the insects feed on the blood of an infected individual and spread the pathogen via saliva during a subsequent meal. son. (1)

The bacterium is not transmitted from person to per-

Let's sense beforehand a labour approach of the disease in workers who realize constant displacements to endemic zones and we analyze your possible consequences

\section{KEY WORDS}

Bartonelosis, Carrión diseases, ward peruana, lutzomyia, occupational bartonella, work disseases. 


\section{HISTORIA}

La bartonelosis conocida como enfermedad de Carrión o Verruga Peruana constituye una endemia ancestral que afecta a la población de valles interandinos y algunas áreas de selva alta. Esta enfermedad fue conocida por culturas precolombinas, tal como se ha podido determinar en algunos huacos y monolitos de la época. (1)

En la conquista de América las tropas españolas sufrieron las "fiebres y verrugas" de Coaque, siendo diezmados muchos de ellos.

En la época de la República (1870-1906) se registra una grave epidemia durante la construcción del ferrocarril Lima - La Oroya (el más alto del mundo), en ella participaron miles de trabajadores (chilenos, chinos, bolivianos, etc.) de los cuales fallecieron más de 7,000 siendo la enfermedad conocida como "Fiebre de la Oroya"; en algunos sobrevivientes aparecieron erupciones dérmicas rojizas, a las que se dio el nombre de verruga peruana. Esta epidemia motivó un gran interés de investigación en la comunidad médica internacional. (1)

En 1885, el estudiante de medicina peruano Daniel Alcides Carrión investiga y establece la unidad clínica existente entre la fiebre de la Oroya y la verruga peruana, constituyéndose así en el mártir de la medicina peruana.

En 1905, el médico peruano Alberto Barton aisló y describió a la Bartonella bacilliformis como agente etiológico responsable de la enfermedad de Carrión o verruga peruana.

En 1913, Townsend identificó a la Lutzomyia verrucarum como el vector responsable de la enfermedad.

La enfermedad de Carrión siempre fue considerada una enfermedad histórica, anecdótica y enigmática, y ha sido estudiada no sólo por peruanos sino también por extranjeros, algunos de los cuales se han especializado en este microorganismo.

\section{DISTRIBUCION GEOGRAFICA}

La enfermedad de Carrión constituye una enfermedad endémica en Sudamérica y sólo se ha reportado en el Perú (Ancash, Cajamarca, Lima, etc.), Ecuador (Loja), Colombia (Nariño); en Tailandia y Sudán se han descrito cuadros similares.

La bartonelosis humana requiere condiciones especiales para su desarrollo y presentación; en el
Perú, las áreas verrucógenas se dan en una extensa área entre los $2^{\circ}$ de latitud norte y $13^{\circ}$ de latitud sur de la vertiente occidental de los Andes; se estima una población de 1'686,236 habitantes que residen en estas áreas endémicas, las cuales abarcan un área de $144,496 \mathrm{Km}^{2}$.

Clásicamente los nichos verrucógenos se localizan entre los 500 - 3,200 m.s.n.m., pero debido a cambios ecológicos y otras variables epidemiológicas la enfermedad se ha encontrado en áreas de la costa y selva. (7)

\section{BACTERIOLOGÍA}

La Bartonella bacilliformis es una bacteria aeróbica Gram negativa intracelular pleomórfica móvil, con especial tropismo por el glóbulo rojo.

Para su observación se emplean técnicas de coloración Giemsa o Wright, se requiere de medios de cultivos especiales, siendo la temperatura óptima de desarrollo de $25^{\circ} \mathrm{C}$ a $28^{\circ} \mathrm{C}$.

En estos cultivos se ha visto que la bacteria posee flagelos unipolares; a la ME, dichos flagelos poseen una longitud de onda de $800 \mathrm{~nm}$; se sabe que los filamentos flagelares están compuestos de polipéptidos de $42 \mathrm{~K}-\mathrm{Da}$, y esta disposición determina su movimiento como "tirabuzón", el cual le permite penetrar con facilidad a los glóbulos rojos. (10)

\section{TRANSMISIÓN}

La bartonelosis en el humano es transmitida por la picadura de mosquitos hematófagos del género Lutzomyia (Lutzomyia verrucarum, peruensis, serrana, etc.), conocida popularmente como "titira" o "manta blanca". La Bartonella bacilliformis se multiplica rápidamente en reservorios humanos durante la fase aguda de la enfermedad y permanece durante periodos prolongados en las personas convalecientes. No se ha demostrado la existencia de reservorios silvestres, siendo el hombre enfermo y no tratado el único reservorio conocido. (2)

La Lutzomyia verrucarum, vector principal de la verruga peruana, es una especie propia del Perú; se encuentra en los valles occidentales e interandinos de los Andes peruanos, también en las casas (dormitorios), en los ambientes peri domiciliarios y en menor cantidad en el campo abierto.

Tiene un patrón estacional, el cual obedece a las diferentes condiciones climáticas de las zonas; 
aumenta en número a partir del mes de marzo a junio.

Las Lutzomyias reposan de día y a partir de las 6 de la tarde en adelante salen a alimentarse; no se conoce el lugar de cría y presentan cuatro estadíos larvares, la temperatura óptima fluctúa entre los $19^{\circ} \mathrm{C}-23^{\circ} \mathrm{C}$; el tiempo de vida del mosquito es en promedio de 50 a 60 días. (3)

\section{CLINICA}

La Lutzomyia verrucarum introduce el huésped la Bartonella bacilliformis; estos microorganismos se localizan principalmente en los endotelios capilares y linfáticos ("células de Strong") y luego penetran activamente a los glóbulos rojos, residiendo dentro de ellos (endoglobulares); ello estimula el sistema retículo endotelial, haciendo que los linfocitos y macrófagos produzcan una intensa eritrofagocitosis del complejo hematíe-bartonella, lo cual puede llevar a una severa anemia de tipo hemolítico y extravascular.

Una vez que un paciente susceptible es picado por el insecto transmisor, este puede cursar sin síntomas o desarrollar diferentes y variados síndromes clínicos.

Clásicamente se han descrito tres periodos: la fase aguda anemizante, le sigue el período denominado intercalar, usualmente asintomático y de duración variable, y luego de meses a años, la fase eruptiva o crónica más conocida como verruga peruana.

Estudios recientes han demostrado que los pacientes pediátricos y adultos jóvenes son los más afectados; en relación al sexo predomina el masculino en ambas fases; respecto al tiempo de enfermedad, la mayoría de los pacientes en fase aguda presentan un menor tiempo de enfermedad y un mayor tiempo los pacientes de fase eruptiva.

El período de incubación clásicamente han sido considerados 21 días, pero según nuestros estudios, la media es de 2 meses. (13)

\section{A) FASE AGUDA}

De inicio brusco o insidioso, dura aproximadamente cuatro semanas. Los síntomas de la fase aguda son diversos, destacando los de un proceso infeccioso general, tales como fiebre, malestar general, palidez, hiporexia; desarrollando anemia severa, hepatomegalia, ictericia, linfoadenomegalia; en oca- siones pueden presentar derrame pericárdico, anasarca, convulsiones.

La depresión transitoria de la inmunidad celular durante la fase aguda explica la presencia de algunas infecciones oportunistas, como son la reactivación de la toxoplasmosis. Las complicaciones mas frecuentes son las producidas por los microorganismos oportunistas (parasitarias, bacterianas y micóticas), tales como Salmonellas tíficas y no tíficas, Plasmodium vivax, Mycobacterium tuberculosis, Pneumocystis carini, Toxoplasma, Histoplasma, etcétera (2)

\section{B) FASE ERUPTIVA}

La fase crónica eruptiva conocida como verruga peruana es muy frecuente a nivel pediátrico; muchos niños preescolares y escolares de las zonas endémicas presentan en cara, extremidades superiores e inferiores diversas formas de verrugas. (12)

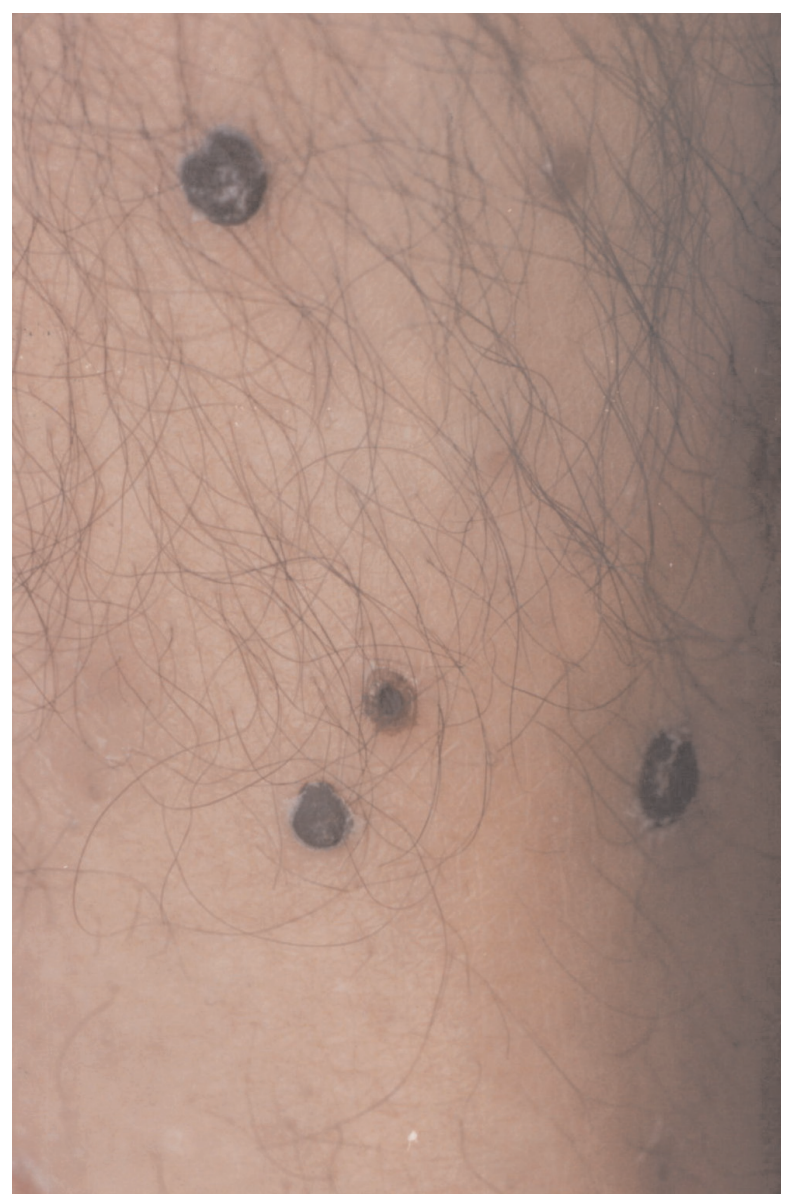

Fase eruptiva 


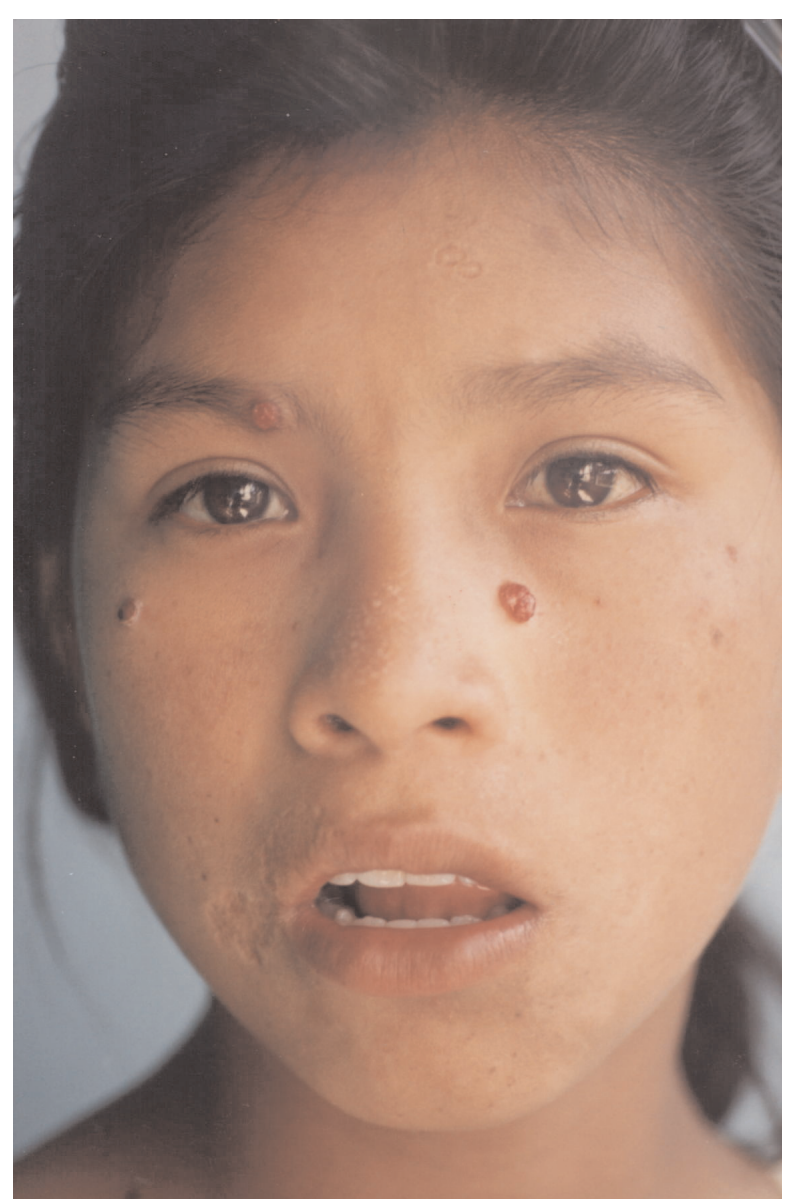

Fase mular

Las formas descritas son:

Miliar (pequeñas), mular (grandes) y nodular (subdérmicas); estas muchas veces curan solas en 3 a 6 meses; ocasionalmente se ha detectado en algunos pacientes (13\%)con verruga peruana, presencia de Bartonellas en sangre sin cuadro anémico severo.

Los signos y síntomas que destacan son: sangrado de las verrugas, palidez leve, fiebre, malestar, prurito, dolor articular, linfoadenomegalia.

La letalidad es excepcional en esta fase. Las lesiones eruptivas se confunden con tumores cutáneos, tales como: granuloma piogénico, angiomatosis bacilar, varicela, molusco contagioso, sarcoma de kaposi, hemangioma, tumor de Spitz, fibrosarcoma, etc. (8)

\section{HISTOPATOLOGÍA}

La reacción histológica de la verruga peruana se caracteriza por la proliferación de células endote-

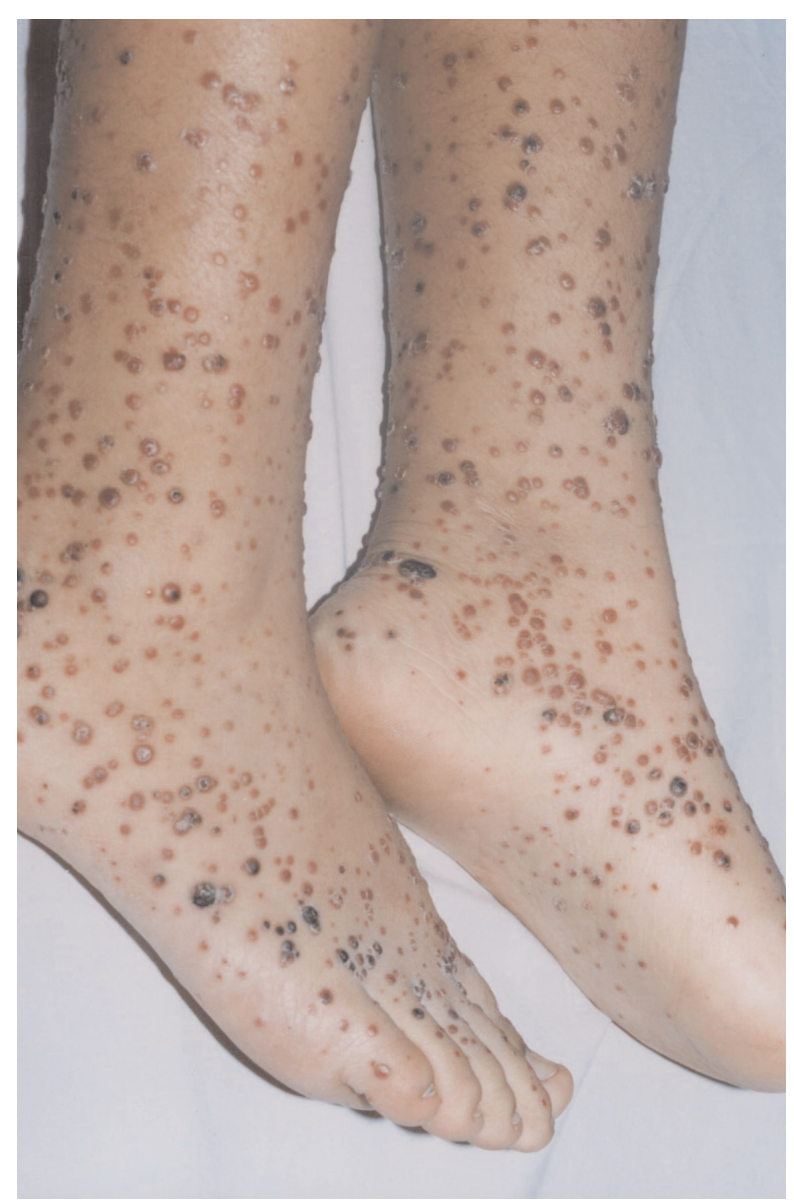

Forma miliar diseminada

liales y monocitos macrófagos; el número de mitosis es variable, en algunos casos son numerosos y están asociados a atipias celulares, dando una imagen histológica similar a una neoformación maligna. (4)

Arias Stella revela en estudios patológicos intensa proliferación de capilares neoformados y marcada hiperplasia endotelial; dentro de estas células existen inclusiones de Rocha Lima de color rojo o violáceo, constituídas por el citoplasma de estas células. (5)

Estudios inmunohistoquímicos realizados por Pierard y Arrese, con anticuerpos monoclonales y policlonales, han permitido conocer mejor la composición celular del verrucoma; así la lesión eruptiva está compuesta por dos poblaciones celulares:

Células endoteliales y dendrocitos dérmicos, en estrecha interrelación anatómica, juegan un rol importante fagocitario en las infecciones bacterianas como la verruga peruana. (6) 


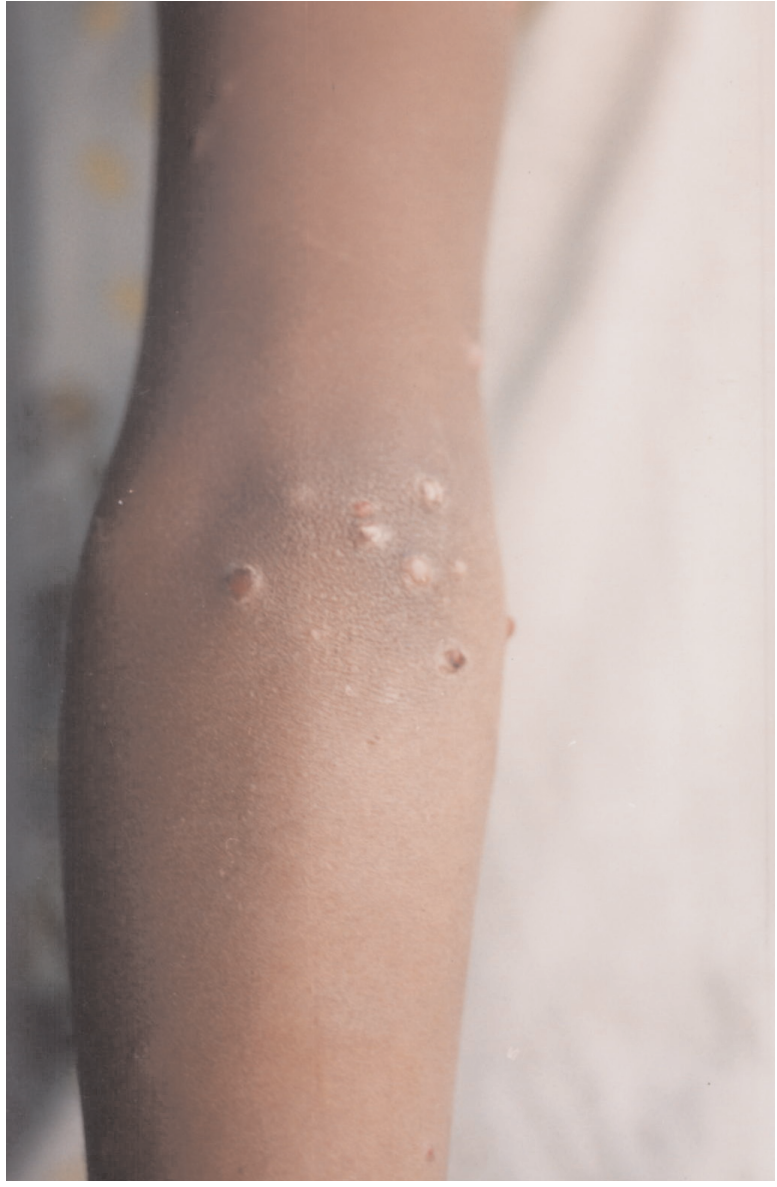

Forma miliar localizada

La presencia de estas poblaciones celulares sitúa a la verruga peruana dentro del grupo de las angiomatosis dendrocíticas.

\section{DIAGNOSTICO}

Uno de los aspectos más importantes en el diagnóstico de la enfermedad es el antecedente epidemiológico; si bien desde hace varias décadas se sabe que la mayoría de los pacientes que desarrollan la fase aguda son foráneos, en los últimos años cada vez más personas nativas presentan esta fase; esto es de particular importancia en los rebrotes de la enfermedad.

En la fase aguda de la bartonelosis el diagnóstico es básicamente a través del frotis sanguíneo, en el cual se observa un $100 \%$ de parasitismo de los glóbulos rojos, que muestran formas bacilares (jóvenes), cocoides (viejas) o cocobacilares.

El hemograma muestra leucocitosis con desviación izquierda, la gran mayoría desarrollan anemia severa (Hcto. $<20 \%$ ) de carácter hemolítico.

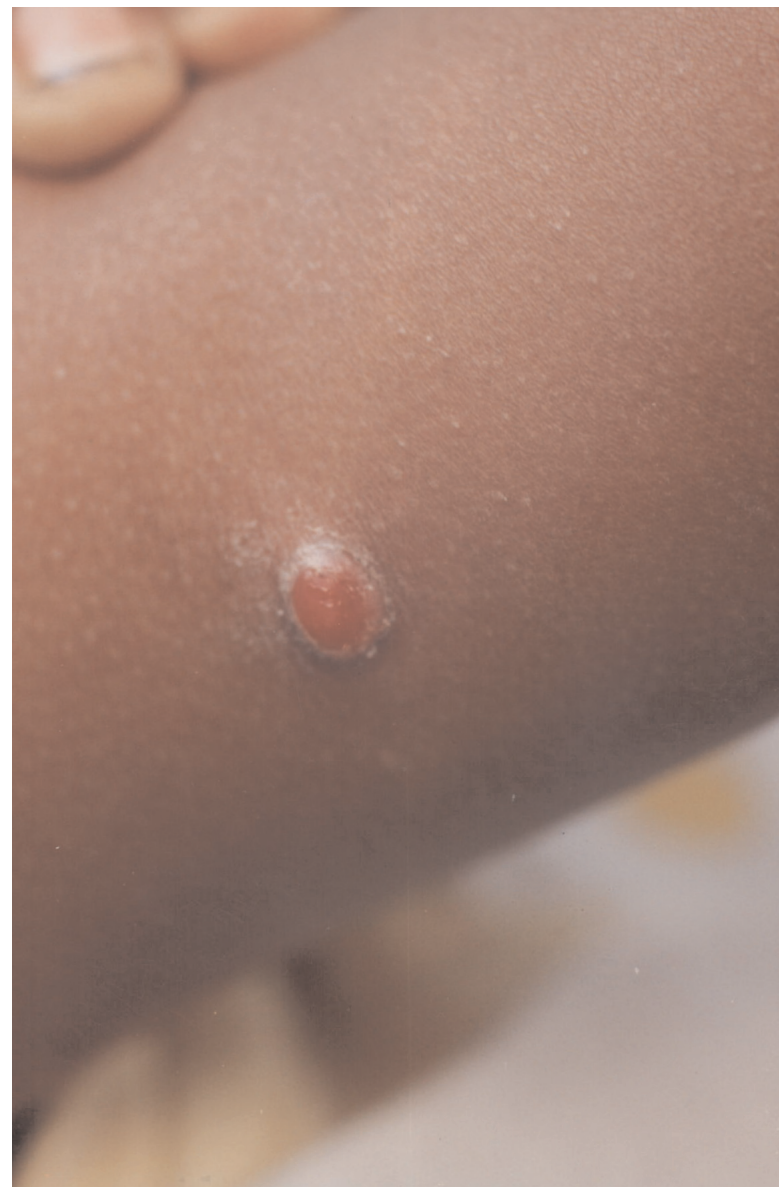

Forma nodular

Como respuesta a la mayor destrucción hemática se da una hiperplasia del tejido eritropoyético de la médula ósea y eventualmente de otros órganos, como el bazo.

El hemocultivo y el mielocultivo en medios especiales son útiles para confirmar el diagnóstico.

El análisis de las pruebas hepáticas revela un compromiso importante en los pacientes en fase aguda; $60 \%$ de estos pacientes tienen valores aumentados de las bilirrubinas, con predominio de la bilirrubina directa.

Se demuestra que la prueba de ELISA cuando se analiza toda la fracción de la bacteria tuvo alta positividad (95.2\%), al igual que el Western Blot: el $100 \%$ de las muestras fueron positivas.

Recientemente se han utilizado la técnica de PCR para detectar la bacteria, en especial cuando hay poco parasitismo en sangre. 
Ultimos estudios de Western Blot realizados por Kosek y cols. Demuestran que esta prueba tuvo mayor positividad en los pacientes eruptivos que los agudos. (11)

\section{TRATAMIENTO}

La mortalidad fue más del $90 \%$ en la era pre antibiótica; actualmente la letalidad es de $8.8 \%$, pero sigue siendo un problema de salud pública.

El tratamiento en la fase aguda es muy efectivo con antibióticos como Cloranfenicol solo o combinado con penicilinas; el uso de Ciprofloxacino es de gran utilidad.

Clásicamente en la fase eruptiva se usó para el tratamiento la Estreptomicina, pero se ha demostrado que la Rifampicina logra en un menor tiempo disminución y desaparición de las verrugas; en los últimos años Ciprofloxacino también se ha usado con éxito. (13)

\section{PREVENCIÓN Y CONTROL}

Clásicamente, la principal y única medida de control ha sido la fumigación con DDT, la cual produjo una disminución importante de los casos, pero últimamente la enfermedad se ha mantenido e incluso han existido rebrotes en algunas zonas endémicas, probablemente por resistencia al DDT. (1)

\section{CONCLUSIONES}

Es de imperiosa necesidad llamar la atención en el mundo científico internacional sobre la importancia de esta enfermedad, que en verdad tiene características especiales.

Es bifásica, con dos estadíos muy disímiles; sólo ataca a la especie humana, sin que hasta hoy se conozca el reservorio animal de los gérmenes causantes; produce en la piel y algunas mucosas un modelo singular de reacción tisular, que es morfológicamente diferente a las reacciones inflamatorias usuales; el agente transmisor es un mosquito hematófago (hembra) del género Lutzomyia, que es cosmopolita; durante la primera fase de invasión sanguínea, con anemia hemolítica severa, hay depresión de la inmunidad; en fin, la distribución está en sitios muy limitados, seguramente en relación con la confluencia de factores ecológicos hasta ahora desconocidos.

Desde épocas anteriores muchos investigadores pensaron y plantearon que la enfermedad estaba controlada e iba camino a la desaparición, pero ello no ha sucedido, la enfermedad de Carrión sigue siendo un problema de salud pública, continúa causando decenas de muertes y todavía existen muchos vacíos en su epidemiología, su patogenia y en la clínica.

Se requieren nuevos estudios longitudinales y a largo plazo para conocer mejor la historia natural de la bartonelosis.

La enfermedad de Carrión, como se menciona en las crónicas, afectaba normalmente a obreros foráneos que acudían a zonas endémicas a realizar trabajos; este fenómeno se da en la actualidad con el desplazamiento constante de trabajadores como mineros, agricultores, construcción civil, profesores, etc., y por la falta de inmunidad están en grave riesgo de hacer la enfermedad luego de varios meses.

No existen registros del tiempo de permanencia de los trabajadores, pero si hay evidencias que son desplazamientos continuos por motivos laborales.

Según la definición de enfermedad ocupacional, diremos que es toda afección directa o indirectamente causada, condicionada, mantenida o agravada por todo aquello que sea utilizado en la actividad profesional o exista en el ambiente de trabajo. (9)

Basados en este concepto planteamos que sería útil y necesario que los organismos competentes reconozcan a la bartonelosis como una enfermedad ocupacional.

Actualmente Perú, Ecuador y Colombia son países endémicos de esta enfermedad y debido a la crisis económica que sufren, muchas personas emigran a otros países con mayor frecuencia a Estados Unidos y Europa (España).

Reportamos esta enfermedad con un enfoque laboral, siendo importante el conocimiento de la enfermedad en estas comunidades ante la posibilidad de registrarse algún caso de bartonelosis en la población de inmigrantes. 


\section{BIBLIOGRAFÍA}

1. Maguiña Vargas Ciro. Bartonellosis o Enfermedad de Carrión, nuevos aspectos de una vieja enfermedad. Primera edición, 1998.

2. Maguiña C. Garcia P. Gotuzzo E. Cordero L. Spach D. Bartonellosis (Carrion's Disease) in the modern era. Infect. Dis. Clin. North Am. 2001 : 33.

3. Maguiña C. y Gotuzzo E. Bartonellosis: new and old. Infect. Dis. Clin. North Am. 2000; 14: 1-22.

4. Arias Stella J. Liebereman PH, Erlandson RA, Arias Stella JJ. Histology, immunohistochermistry and ultrastructure of the verruga in Carrion's disease. Am. J Surg Pathol 1986; 10: 596-610.

5. Arias Stella J. Y Arias Stella C. Las inclusiones de Rocha Lima en la verruga peruana. Folia Dermatológica Peruana 1996; $7: 1-5$.

6. Arrese Estrada J., Maguiña C., Pierard G. La verruga peruana: pasado, presente y futuro. Piel 1992; 7(7); 350-353.

7. Cáceres A. Límite meridional de Lutzomya verrucarum. Towsend, 1993, en la cuenca del Pacífico. Diagnóstico 1985; 15 (2) : 42-44.
8. Cáceres Ríos H, Rodríguez J, Maguiña Vargas C, Bravo F, Díaz CS, Ramos D. Verruga peruana: an infectious endemic angiomatosis. Crit Rev Onc 1995;6(1): 47-56.

9. Conde-Salazar G, Luis; Ancona A, Armando. Dermatología Profesional Edit.Aula Médica, 2004.

10. Colichón H. Bartonella bacilliformis en la sangre periférica de los pobladores de las zonas verrucógenas del Perú. Rev Per de Med Trop 1972; 1 (1) :19-21.

11. García -Cáceres U y García FV. Bartonellosis, an immunodepressive disease and the like of Daniel Alcides Carrion. Am J Clin Pathol 1991; 95 (supl 1); 58-66.

12. Maguiña C y Gotuzzo E. Verruga Peruana o Enfermedad de Carrión. Libro Pediatría Menengheloo. Chile, cuarta edición 1991; 1: 696-697.

13. Maguiña C. Bartonellosis humana en el Perú Estudio de 145 pacientes de Bartonellosis en el Hospital Nacional Cayetano Heredia. Tesis Doctoral, UPCH. 1993.

14. Vizcarra H. La Bartonella de Alberto Barton y las nuevas Bartonellas. Folia Dermatológica Peruana 1999; 8 (4); 15-20. 